\title{
Magneto-Impedance Effect of Composite Wires Prepared by Chemical Plating under DC Current
}

\author{
D. L. Chen, X. Li, H. L. Pan, H. Y. Luan, Z. J. Zhao
}

(Received 03 January 2014; accepted 13 March 2014; published online July 1, 2014)

\begin{abstract}
CuBe}$ composite wires of $100 \mu \mathrm{m}$ in diameter coated with a layer of NiCoP were prepared by a chemical plating method under DC current (CPUDC). The influences of DC current on coating morphology, deposition rate, composition, giant magneto-impedance (GMI) effect and magnetic properties were investigated. It was shown that the circumferential domain structure of coating layer was induced by the DC current going through the wires. A maximum GMI ratio of $870 \%$ was obtained in the composite wire prepared under 150 $\mathrm{mA}$ and tested at $180 \mathrm{kHz}$. It is 30 times higher than that of the composite wire plated in the same condition by conventional chemical plating method, indicating that CPUDC is an easy and effective approach to obtain composite wires and its applications will be further extended on magnetic sensors.
\end{abstract}

Keywords: GMI; Chemical plating; Magnetic properties

Citation: D. L. Chen, X. Li, H. L. Pan, H. Y. Luan and Z. J. Zhao, "Magneto-Impedance Effect of Composite Wires Prepared by Chemical Plating under DC Current", Nano-Micro Lett. 6(3), 227-232 (2014). http://dx. doi.org/10.5101/nml140024a

\section{Introduction}

Recently, giant magneto-impendence (GMI) effect has been intensively studied for its potential applications in highly sensitive magnetic sensors with high spatial/temporal resolution since it was firstly observed in Co-based amorphous wires in 1992 [1,2]. Experimental and theoretical results confirmed that the origin of the GMI is classical skin effect [4-6]. Although the studies on GMI effect was initially focused in homogeneous materials [1-3], great attention has been paid to the heterogeneous materials such as composite wires and sandwiched films $[7,8]$, since it has great advantages over the homogeneous materials such as [9]: (1) the GMI effect was enhanced obviously, which results from the enhanced skin effect of the coating layer caused by electromagnetic interactions between the conductive and ferromagnetic layers; (2) the MI effect can be observed at much lower frequencies; and (3) realization of miniaturization and practicability for sensors.
Commonly, the composite wires were fabricated by magnetron sputtering [11], electroplating [12-16], chemical plating [17], or MEMS technique [18]. However, the GMI sensitivity of the composite wires is not high since their magnetic structure cannot be well controlled by these methods. It was found that GMI sensitivity could be increased through subsequent processes such as tensile stress annealing treatment $[19,20]$ and Joule annealing treatment [21].

In this paper, a new technique based on chemical plating was proposed and $\mathrm{NiCoP} / \mathrm{CuBe}$ composite wires were fabricated. DC current was applied on the wire during the plating process. The influence of $\mathrm{pH}$ value of the plating bath and the current magnitude on GMI effect and magnetic structure of the wires were analyzed.

\section{Experimental details}

All chemicals used in this work were purchased from

Department of Physics, Engineering Research Center for Nanophotonics \& Advanced Instrument, Ministry of Education, East China Normal University, Shanghai 200062, China

*Corresponding author. zjzhao@phy.ecnu.edu.cn (Z. J. Zhao) 
Sinopharm Chemical Reagent Co., Ltd. (China). Nickelous sulfate $\left(\mathrm{NiSO}_{4} \cdot 6 \mathrm{H}_{2} \mathrm{O}\right)$, cobalt sulfate $\left(\mathrm{CoSO}_{4} \cdot 7 \mathrm{H}_{2} \mathrm{O}\right)$, sodium tartaric $\left(\mathrm{Na}_{2} \mathrm{C}_{4} \mathrm{H}_{4} \mathrm{O}_{6} \cdot 2 \mathrm{H}_{2} \mathrm{O}\right)$, ammonium sulfate $\left(\left(\mathrm{NH}_{4}\right)_{2} \mathrm{SO}_{4}\right)$, sodium hypophosphite $\left(\mathrm{NaH}_{2} \mathrm{PO}_{2} \cdot \mathrm{H}_{2} \mathrm{O}\right)$, stannous chloride dehydrate $\left(\mathrm{SnCl}_{2} \cdot 2 \mathrm{H}_{2} \mathrm{O}\right)$, palladium chloride $\left(\mathrm{PdCl}_{2}\right)$ were used without further purification.

The composite wires were prepared by chemical plating under DC current (CPUDC) along a CuBe wire in diameter of $100 \mu \mathrm{m}$. Firstly, the wire was rinsed in hydrochloric acid $(6 \mathrm{~mol} / \mathrm{L} \mathrm{HCl})$ for $5 \mathrm{~min}$, followed by sensitization in sensitizing solution $(0.11$ $\mathrm{mol} / \mathrm{L} \mathrm{SnCl} 2 \cdot 2 \mathrm{H}_{2} \mathrm{O}, 0.48 \mathrm{~mol} / \mathrm{L} \mathrm{HCl}$ ) for $5 \sim 10 \mathrm{~min}$ and activation in activate fluid $\left(2.8 \times 10^{-4} \mathrm{~mol} / \mathrm{L}\right.$ $\left.\mathrm{PdCl}_{2}, 0.48 \mathrm{~mol} / \mathrm{L} \mathrm{HCl}\right)$ for $10 \mathrm{~min}$. The plating solution consists of $\mathrm{NiSO}_{4} \cdot 6 \mathrm{H}_{2} \mathrm{O}(0.025 \mathrm{~mol} / \mathrm{L})$, $\mathrm{CoSO}_{4} \cdot 7 \mathrm{H}_{2} \mathrm{O}(0.035 \mathrm{~mol} / \mathrm{L}), \mathrm{Na}_{3} \mathrm{C}_{6} \mathrm{H}_{5} \mathrm{O}_{7} \cdot \mathrm{H}_{2} \mathrm{O}(0.10$ $\mathrm{mol} / \mathrm{L}), \mathrm{C}_{4} \mathrm{H}_{4} \mathrm{O}_{6} \mathrm{Na}_{2} \cdot 2 \mathrm{H}_{2} \mathrm{O}(0.15 \mathrm{~mol} / \mathrm{L}),\left(\mathrm{NH}_{4}\right)_{2} \mathrm{SO}_{4}$ $(0.50 \mathrm{~mol} / \mathrm{L}), \mathrm{NaH}_{2} \mathrm{PO}_{2} \cdot \mathrm{H}_{2} \mathrm{O}(0.30 \mathrm{~mol} / \mathrm{L})$ and different contents of $\mathrm{NaOH}$. After fully mixing the plating solution, the chemical plating process was carried out by the conventional method and CPUDC method, respectively. The temperature of the plating bath was kept at $363 \pm 1 \mathrm{~K}$ and the $\mathrm{pH}$ value was adjusted in the range of $8.0 \sim 8.8$ by adding $\mathrm{NaOH}$ dropwise, while the DC current varied from $0 \mathrm{~mA}$ to $250 \mathrm{~mA}$.

The morphology and thicknesses of the core and the plated layer were observed using scanning electron microscopy (SEM, RILIs-4800). The composition of the plated layer under each DC current was determined using an energy dispersive X-ray (EDX) device. The hysteresis loops were tested using a Lakeshore 7404 vibrating sample magnetometer (VSM). The magnetoimpedance measurement of the composite wires in length of $4 \mathrm{~cm}$ was carried out using a precise impedance analyzer (HP 4294A). The RMS value of alternating current was maintained at $10 \mathrm{~mA}$, and its frequency was varied from $100 \mathrm{~Hz}$ to $100 \mathrm{MHz}$. The applied external magnetic field was generated by a pair of Helmholtz coils and the maximum value of external magnetic field was 100 Oe. During the measurements, the composite wires were subjected along the longitudinal direction and vertical to geomagnetic field.

The GMI ratio was defined as

$$
\Delta Z / Z=\frac{Z\left(H_{e x}\right)-Z\left(H_{0}\right)}{Z\left(H_{0}\right)} \times 100 \%
$$

where $Z\left(H_{e x}\right)$ and $Z\left(H_{0}\right)$ are the sample impedance values under a magnetic field of $H_{e x}$ and 0 Oe, respectively. The maximum applied magnetic field was 100 Oe.

\section{Results and discussion}

Figure 1 shows the GMI effect curves tested at 400 $\mathrm{kHz}$ for the composite wires prepared by conventional chemical plating under different $\mathrm{pH}$ values. Initially, the $M I$ ratio increases with $H_{e x}$ to a maximum value, and then decreases with further increase of the field. It means that the easy axis of the coating layer is orientated in circumferential direction [3]. However, the field sensitivity defined as $d(\Delta Z / Z) / d H_{e x}$ is not high, which means that the moment direction deviates from the circumferential direction. When the $\mathrm{pH}$ value was increased from 8.0 to 8.8, the maximum $M I$ ratio increases from $8.9 \%$ to $24.3 \%$, and then decreased to $17.0 \%$. The $\mathrm{pH}$ value of the bath may change the composition and magnetic properties of the coating layer. It is evident that the highest $M I$ ratio was obtained when $\mathrm{pH}$ value is 8.4. The optimal $\mathrm{pH}$ value is much higher than that of electroplating method [13-16,22]. The $\mathrm{pH}$ value was kept at 8.4 in the following CPUDC method.

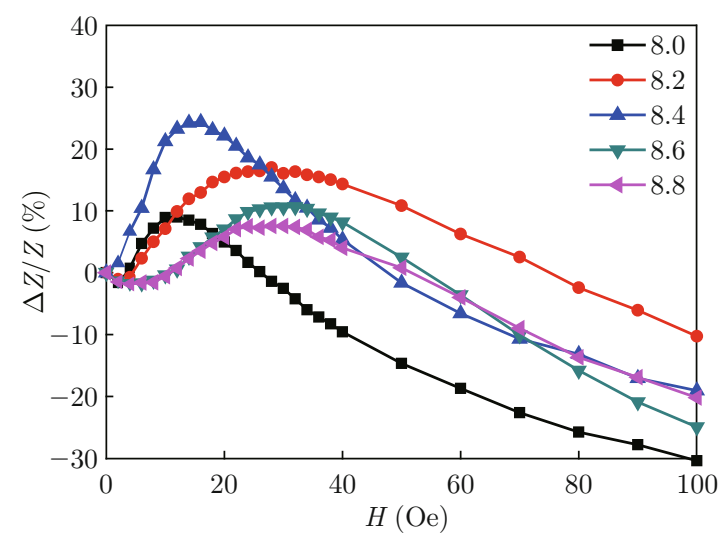

Fig. 1 Field dependence of the GMI ratio of the composite wire under different $\mathrm{pH}$ values tested at $400 \mathrm{kHz}$.

Figure 2(a) shows the surface morphology of CuBe wire before deposition. The surface is smooth and uniform. Figure 2 shows the surface morphology of composite wires prepared by conventional chemical plating (Fig. 2(b)) and under DC current of $50 \mathrm{~mA}$ (Fig. 2(c)) or $250 \mathrm{~mA}$ (Fig. 2(d)). It can be seen that the surface of deposited layer is less smooth and uniform. Evidently, there are tiny holes on the surface of deposited layer because of oxidation-reduction reaction. The number of holes increases with the magnitude of the DC current, giving rise to higher roughness at larger current.

Figure 3 shows the relationship of the deposition rate versus the DC current. It can be seen that the deposition rate increases monotonously with the DC current. The essence of chemical deposition process is oxidation-reduction reaction, associated with the reaction accompanied by electron transfer at the surface of the substrate. With a magnetic field induced by the DC current, the solution near substrate was slightly agitated and the motion of free ions was accelerated because of the microstructure magneto hydrodynamics effect (MHD effect) [22]. Hence, the reaction rate increased by the acceleration of ion motion. This behavior reveals that the deposition rate increases with 

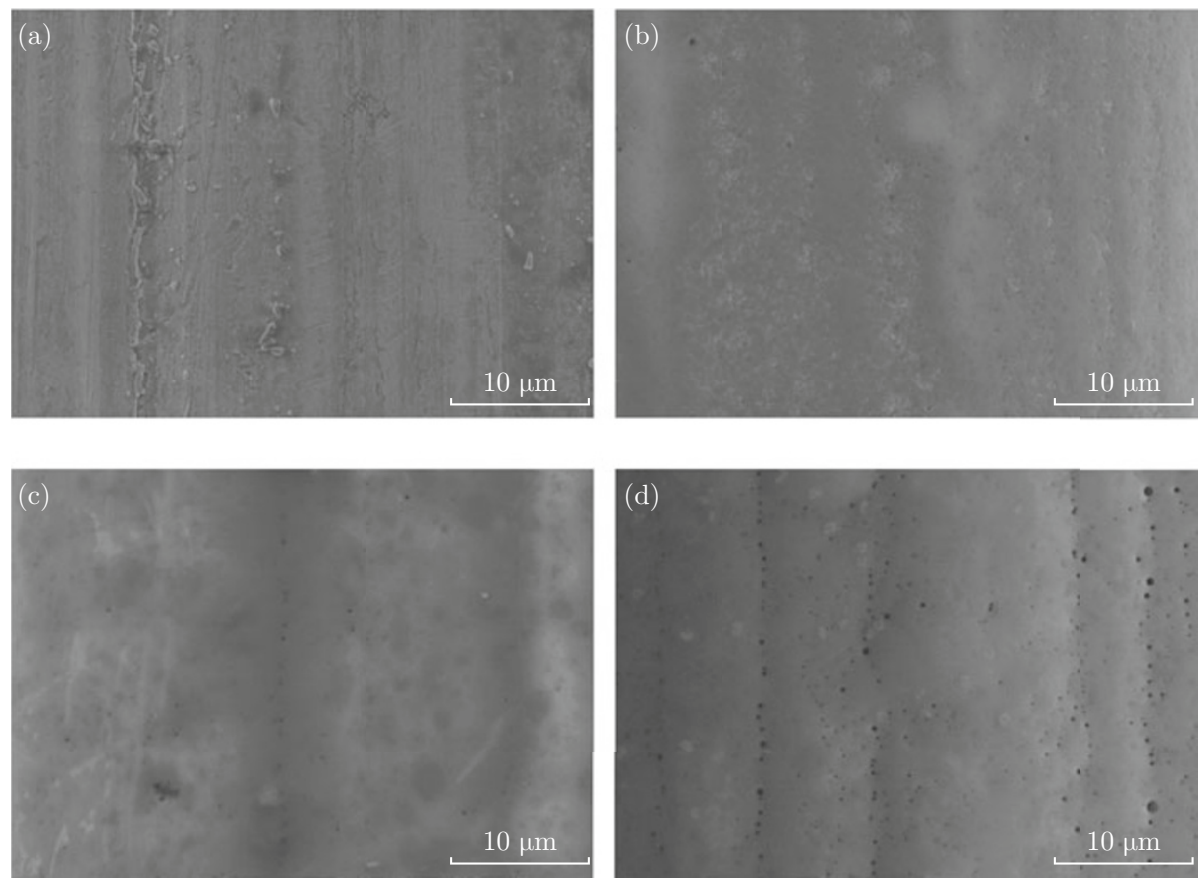

Fig. 2 FESEM images of CuBe wire (a) and the composite wires with DC current of $0 \mathrm{~mA}$ (b); $50 \mathrm{~mA}$ (c); and $250 \mathrm{~mA}$ (d).

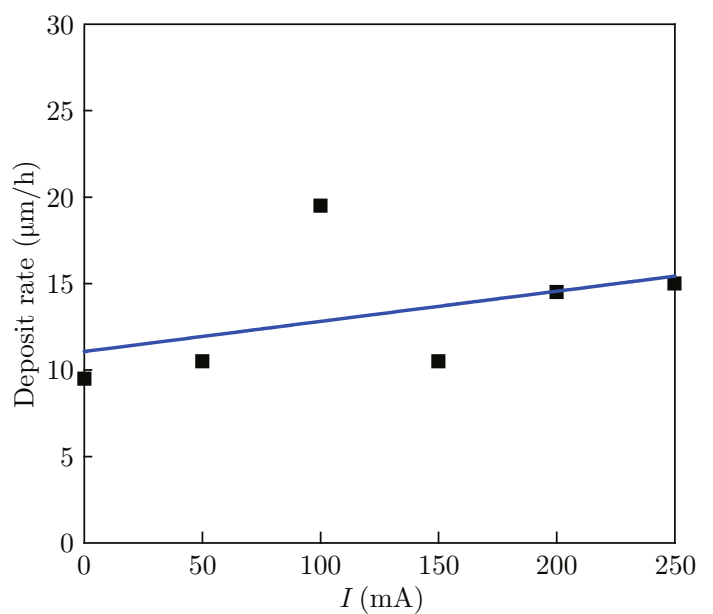

Fig. 3 Effect of DC current on deposition rate of the coating layer.

the augmentation of the induced magnetic field. Nevertheless, the increased DC current induces higher roughness of the surface during oxidation-reduction reaction, which impedes further augmentation of the deposition rate. Consequently, the magnetic field induced by proper DC current, $100 \mathrm{~mA}$ in this work, enhanced the deposition rate significantly due to these two effects.

The composition of the coating layers plated under different DC current was measured by EDX. The current has slight influence on the composition of wires, shown in Fig. 4. Apparently, the variations of the Co, $\mathrm{Ni}$ and $\mathrm{P}$ percentage in the layers plated under the $\mathrm{DC}$ current ranging from $50 \mathrm{~mA}$ to $250 \mathrm{~mA}$ are all small. The average composition of the coating is $\mathrm{Ni}_{27} \mathrm{Co}_{59} \mathrm{P}_{14}$.

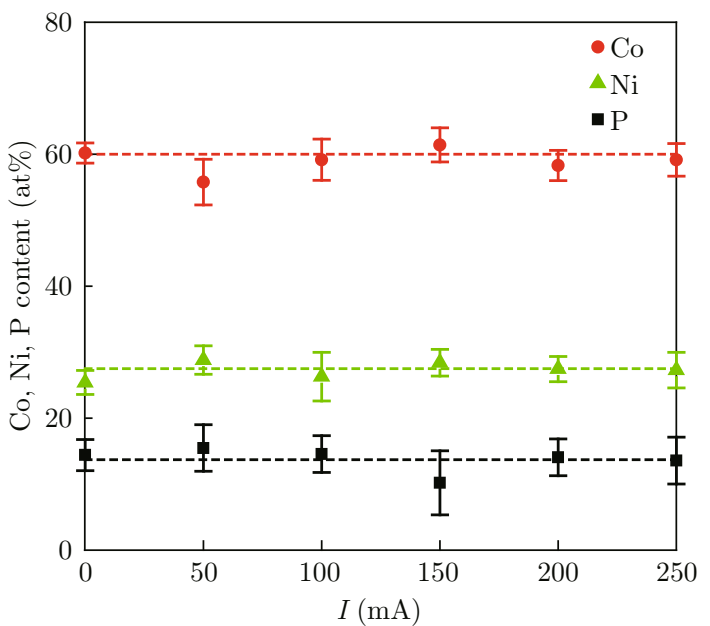

Fig. 4 Effect of DC current on chemical composition of the coating layer.

Figure 5 shows the MI ratio curves tested at $400 \mathrm{kHz}$ for the composite wires plated under different current. It is shown that the MI ratio of the composite wires increases initially and then decreases with the current. A remarkable enhancement of MI ratio occurs at $150 \mathrm{~mA}$. Besides, the field sensitivity of MI curves for the samples with DC current are obviously increased relative to the sample fabricated without current. It reveals that the magnetic domain in these samples are circumferential orientated. Thus, circumferential domain structure in coating layer can be induced by CPUDC method, and the GMI ratio of composite wires prepared using this method improves significantly. 


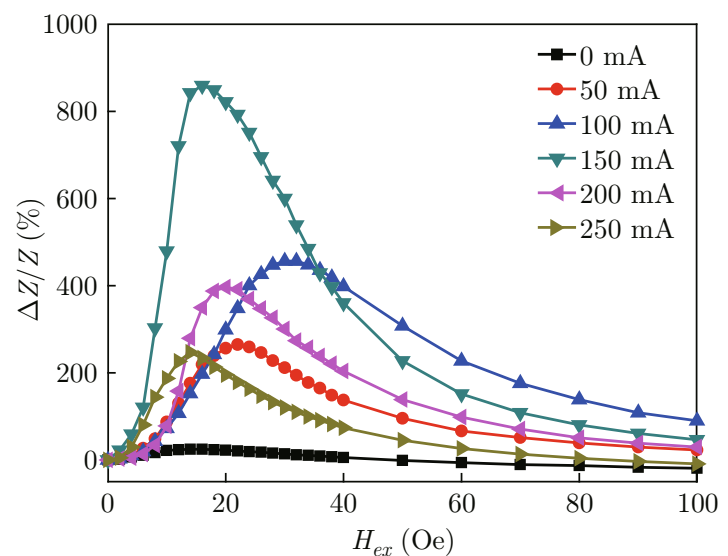

Fig. 5 Field dependence of the GMI ratio of the composite wires prepared by CPUDC method under different DC current.

It is obvious that the maximum GMI ratio increases firstly and then decreases with the increasing of DC current. A maximum GMI ratio of $868 \%$ was obtained for the sample deposited under $150 \mathrm{~mA}$. Though the result is a little lower than the ratio of $1100 \%$ in electroplated $\mathrm{NiFe} / \mathrm{Cu}$ composite wire after Joule annealing, CPUDC is one step method [23]. When the DC current is smaller, the induced circumferential structure may increase the GMI ratio. With further increase of the current, the coating roughness and thickness increased. The induced field decreases with the coating thickness layer according to the Ampere law. Consequently, the magnetic moments direction of the magnetic film may orientate from circumferential direction to longitudinal direction [24]. In addition, thicker coating layer results in smaller dynamic driving field, which leads to the weaker magnetization of the magnetic layer. Both the moment deviation and weaker magnetization can result in the significant decrease of the GMI ratio. As for the current of $150 \mathrm{~mA}$, it is the optimal value to get largest GMI ratio.

In previous study [13,22], GMI effect can be enhanced by Joule annealing which induces circumferential magnetic domain. The corresponding annealing current ranges from several hundred milliamperes to several amperes. In this work, CPUDC method could induce circumferential magnetic domain structure during the process of sample preparation. Compared to Joule annealing, this method has simplified the experimental set-up. Meanwhile, the amplitude of the current is smaller.

Figure 6 shows GMI spectra of the samples deposited under different DC current. It can be seen that with frequency increasing, the GMI ratio first increases, undergo a peak, and finally drops down. Each sample has a maximum MI ratio at the critical frequency. With the increase of DC current form $50 \mathrm{~mA}$ to $150 \mathrm{~mA}$, the critical frequency decreases from $1.44 \mathrm{MHz}$ to $180 \mathrm{kHz}$. Further increase of the DC current leads to the increase of critical frequency up to $460 \mathrm{kHz}$. The critical frequency mainly depended on the softness and thickness of the coating layer [25]. The lowest critical frequency was obtained in the composite wire plated under 150 $\mathrm{mA}$.

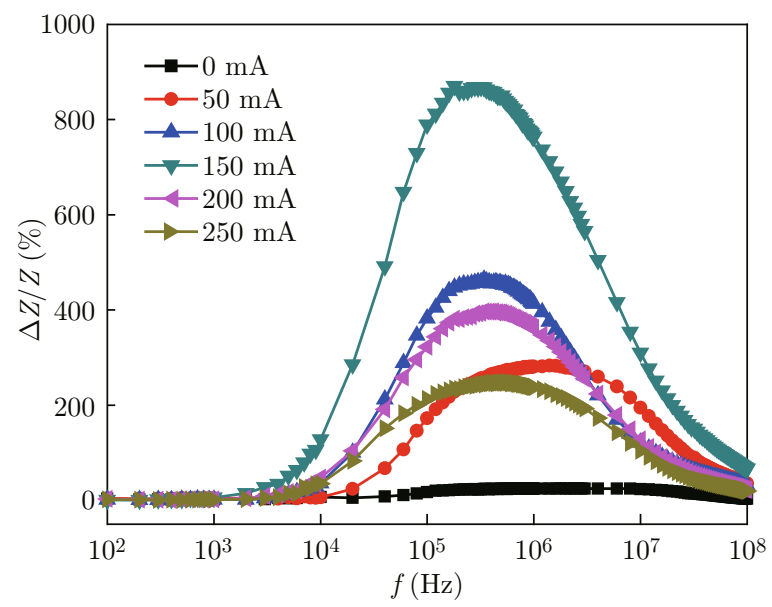

Fig. 6 Frequency dependence of the maximum GMI ratio under different DC current.

Figure 7 shows hysteresis loops of the composite wires mentioned above. It can be seen from the loops that the wire prepared by conventional chemical plating method has some circumferential magnetic structure. Whereas the sample prepared by CPUDC method shows that their coating layer has better circumferential magnetic structure when the current amplitude is below $150 \mathrm{~mA}$. Apparently, for composite wire deposited under 150 $\mathrm{mA}$, the coercivity and the energy loss are both smaller.

It is well known that the peak field value in MI curves is the effective anisotropy field of the ferromagnetic layer. Figure 8 shows the dependence of the maximum MI ratio and anisotropy fields acquired from Fig. 5 and 7 . It can be seen that the $H_{k}$ values have the same variation trend as DC current, though the numerical value itself is not completely identical. It can be also seen that the GMI ratio is not coincident with the $H_{k}$ values. The sample plated under $150 \mathrm{~mA}$ has the maximum MI ratio. However its $H_{k}$ value is not the smallest one. Hence, both of the $H_{k}$ value and domain structure are important for GMI effect. This result agrees well with the above discussion from the MI curves.

\section{Conclusion}

In summary, we have prepared the $\mathrm{NiCoP} / \mathrm{CuBe}$ composite wires by conventional chemical plating method and CPUDC method. It was found that $\mathrm{pH}$ value and DC current had significant effect on GMI effect. The optimal $\mathrm{pH}$ value by conventional chemical plating method is 8.4. The GMI ratio was much enhanced using CPUDC method, because of the induced 


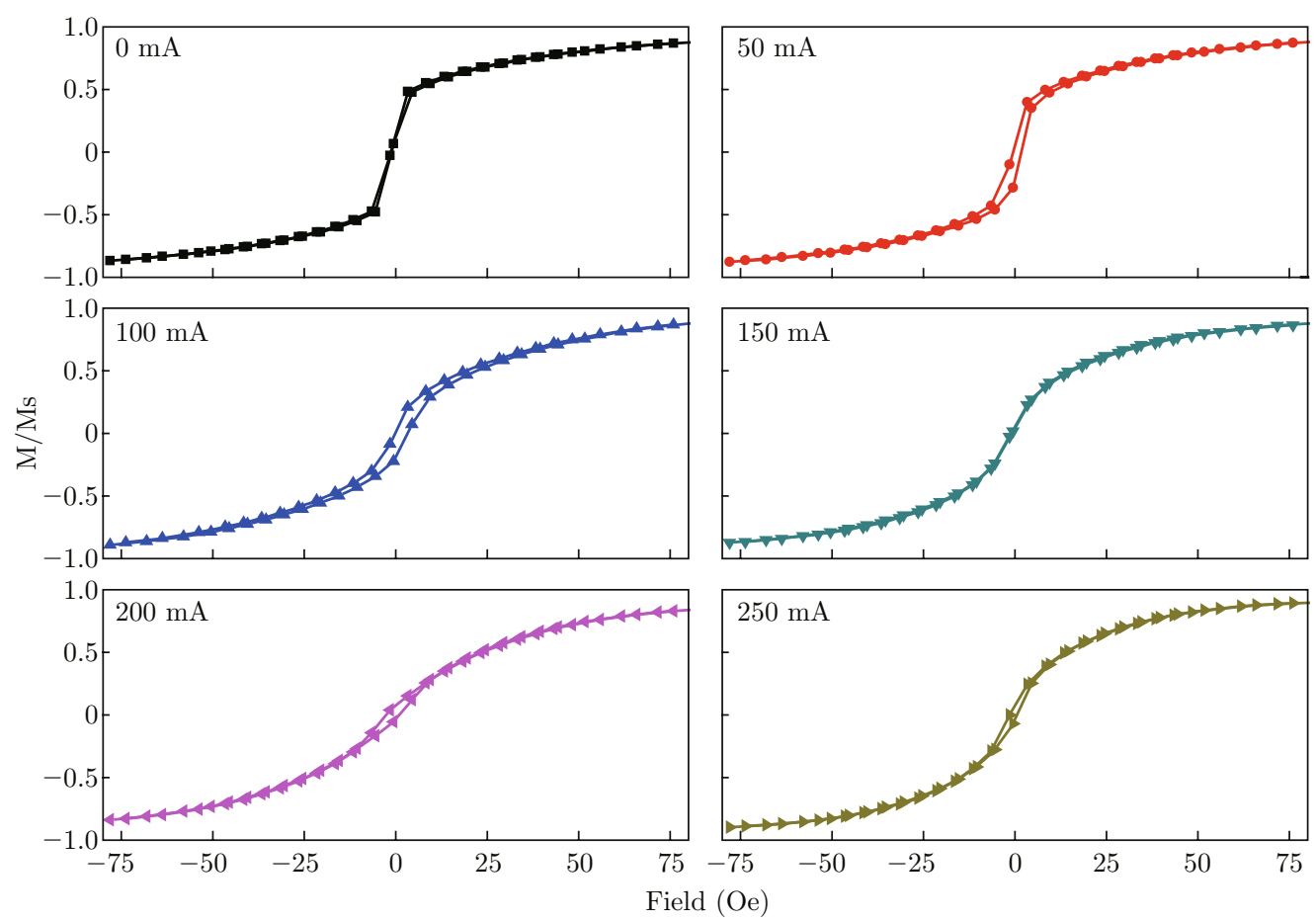

Fig. 7 DC hysteresis loops of composite wires prepared by conventional and CPUDC methods.

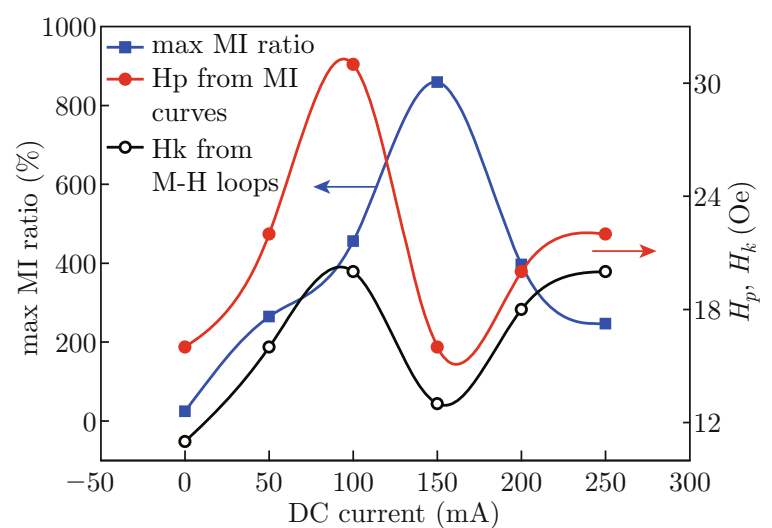

Fig. 8 Dependence of the max GMI ratio and anisotropy field of the composite wires on the DC current.

circumferential domain structure in the coating layer. It was found that GMI ratio reached $870 \%$ when the DC current is $150 \mathrm{~mA}$. The established method with DC current is convenient and effective to enhance the MI ratio and could be used to prepare sensing element for magnetic sensors.

\section{Acknowledgements}

This work was supported by Shanghai Automotive Science and Technology Development Foundation (SAISTDF /12-06), East China Normal University Program (78210142, 78210183), Large Instruments Open Foundation of East China Normal University (201369), National Natural Science Foundation of China
(51302085).

\section{References}

[1] B. Li, N. P. M. Salem, I. Giouroudi and J. Kosel, "Integration of thin film giant magnetoimpedance sensor and surface acoustic wave transponder", J. Appl. Phys. 111(7), 07E514 (2012). http://dx.doi.org/10.1063/ 1.367843

[2] K. Mohri, T. Kohsawa, K. Kawashima, H. Yoshida and L. V. Panina, "Magneto-inductive effect (MI effect) in amorphous wires", IEEE Trans. Magn. 28(5), 31503152 (1992). http://dx.doi.org/10.1109/20.179741

[3] M. H. Phan and H. X. Peng, "Giant magnetoimpedance materials: fundamentals and applications", Prog. Mater Sci., 53(2), 323-420 (2008). http://dx.doi.org/10.1016/j.pmatsci.2007.05. 003

[4] A. Gromov and V. Korenivski, "Electromagnetic analysis of layered magnetic/conductor structures", J. Phys. D: Appl. Phys. 33(7), 773-779 (2000). http:// dx.doi.org/10.1088/0022-3727/33/7/304

[5] A. Chaturvedi, K. Stojak, N. Laurita, P. Mukherjee, H. Srikanth and M. Phan, "Enhanced magnetoimpedance effect in Co-based amorphous ribbons coated with carbon nanotubes", J. Appl. Phys. 111(7), 07E507 (2012). http://dx.doi.org/10.1063/1.3676214

[6] L. V. Panina and K. Mohri, "Magneto-impedance effect in amorphous wires", Appl. Phys. Lett. 65(9), 1189-1191 (1994). http://dx.doi.org/10.1063/1. 112104

[7] M. H. Phan, H. X. Peng, M. T. Tung, N. V. Dung and N. H. Nghi, "Optimized GMI effect in electrode- 
posited $\mathrm{CoP} / \mathrm{Cu}$ composite wires", J. Magn. Magn. Mater. 316(2), 244-247 (2007). http://dx.doi.org/ $10.1016 / j \cdot j \mathrm{mmm} .2007 .02 .111$

[8] L. Chen, Y. Zhou, C. Lei and Z. M. Zhou, "Effect of sputtering parameters and sample size on giant magneto impedance effect in $\mathrm{NiFe}$ and $\mathrm{NiFe} / \mathrm{Cu} / \mathrm{NiFe}$ films", Mater. Sci. Eng. B172(2), 101-107 (2010). http://dx.doi.org/10.1016/j.mseb. 2010.04.026

[9] A. S. Antonov, A. L. Rakhmanov, N. A. Buznikov, A. F. Prokoshin, A. B. Granovsky, N. S. Perov and N. A. Usov, "Magnetic properties and magnetoimpedance of cold-drawn permalloy-copper composite wires", IEEE Trans. Magn. 35(5), 3640-3642 (1999). http://dx.doi.org/10.1109/20.800616

[10] J. S. Liu, J. F. Sun, D. W. Xing, X. Xue, S. L. Zhang, H. Wang and X. D. Wang, "Experimental study on the effect of wire bonding by $\mathrm{Cu}$ electroplating on GMI stability of Co-based amorphous wires", Physica Status Solidi A 208(3), 530-534 (2011). http://dx.doi. org/10.1002/pssa. 201026351

[11] S. Xiao, Y. Liu, Y. Dai, L. Zhang, S. Zhou and G. Liu, "Organic light-emitting diodes (OLEDs): materials, devices and applications", J. Appl. Phys. 85(8), 41274130 (1999). http://dx.doi.org/10.1063/1.370321

[12] R. L. Wang, X. Li, X. H. Kong, Y. X. Guo, J. Z. Ruan and Z. J. Zhao, "Giant magneto-impedance effect in composite wires with different core layer", Nano-Micro Lett. 5(2), 140-144 (2013). http://dx.doi.org/10. $5101 / \mathrm{nml} \cdot \mathrm{v} 5 \mathrm{i2} \cdot \mathrm{p} 140-144$

[13] X. P. Li, Z. J. Zhao, C. Chua, H. L. Seet and L. Lu, "Enhancement of giant magneto impedance effect of electroplated $\mathrm{NiFe} / \mathrm{Cu}$ composite wires by dc Joule annealing", J. Appl. Phys. 94(12), 7626-7630 (2003). http://dx.doi.org/10.1063/1.1628828

[14] H. L. Seet, X. P. Li, W. C. Ng, H. Y. Chia, H. M. Zheng and K. S. Lee, "Development of $\mathrm{Ni}_{80} \mathrm{Fe}_{20} / \mathrm{Cu}$ nanocrystalline composite wires by pulse-reverse electrodeposition", J. Alloys and Comp. 449, 279283(2008). http://dx.doi.org/10.1016/j.jallcom. 2006.02.104

[15] G. V. Kurlyandskaya, E. Kisker, H. Yakabchuk and N. G. Bebenin, "Non-linear giant magnetoimpedance", J. Magn. Magn. Mater. 240(1), 206-208 (2002). http:// dx.doi .org/10.1016/S0304-8853(01)00759-4

[16] F. E. Atalay and S. Atalay, "Giant magnetoimpedance effect in $\mathrm{NiFe} / \mathrm{Cu}$ plated wire with various plating thicknesses" J. Alloys Comp. 392(1), 322328 (2005). http://dx.doi.org/10.1016/j.jallcom. 2004.09 .024
[17] X. Wang, W. Yuan, Z. Zhao, X. Li, J. Ruan and X. Yang, "Giant magneto impedance effect in $\mathrm{CuBe} / \mathrm{NiFeB}$ and $\mathrm{CuBe} /$ insulator/NiFeB electrolessdeposited composite wires", IEEE Trans. Magn. 41(1), 113-115 (2005). http://dx.doi.org/10.1109/TMAG. 2004.832479

[18] Q. Zhang, D. L. Chen, X. Li, P. X. Yang, J. H. Chu and Z. J. Zhao, "Influence of an electronic field on the GMI effect of Fe-based nanocrystalline microwire", Nano-Micro Lett. 5(1), 13-17 (2013). http://dx.doi. org/10.3786/nml. v5i1

[19] S. L. Zhang, J. F. Sun, D. W. Xing, F. X. Qin and H. X. Peng, "Large GMI effect in Co-rich amorphous wire by tensile stress", J. Magn. Magn. Mater. 323(23), 3018-3021 (2011). http://dx.doi.org/10. 1016/j.jmmm. 2011.06.041

[20] J. M. Blanco, A. Zhukov and J. Gonzalez, "Asymmetric torsion stress giant magnetoimpedance in nearly zero magnetostrictive amorphous wires", J. Appl. Phys. 87(9), 4813-4815 (2000). http://dx.doi.org/ 10.1063/1.373168

[21] J. S. Liu, F. Y. Cao, D. W. Xing, L. Y. Zhang, F. X. Qin, H. X. Peng, X. Xue and J. F. Sun, "Enhancing GMI properties of melt-extracted Co-based amorphous wires by twin-zone Joule annealing", J. Alloy. Compd. 541, 215-221 (2012). http://dx.doi.org/10.1016/j. jallcom. 2012.05.126

[22] M. Ipatov, L. Gonzalez-Legarreta, J. Garcia, A. Chizhik, L. Dominguez, V. Zhukova, A. Zhukov, B. Hernando and J. Gonzalez, "Induced giant magnetoimpedance effect by current annealing in ultra thin Co-Based amorphous ribbons", IEEE Trans. Magn. 49(3), 1009-1012 (2013). http://dx.doi.org/ 10.1109/TMAG. 2012.2228473

[23] A. Krause, M. Uhlemann, A. Gebert and L. Schultz, "The effect of magnetic fields on the electrodeposition of cobalt", Electrochim. Acta. 49(24), 4127-4134 (2004). http://dx.doi.org/10.1016/j. electacta.2004.04.006

[24] T. Nakai, H. Abe, S. Yabukami and K. I. Arai, "Impedance property of thin film GMI sensor with controlled inclined angle of stripe magnetic domain", J. Magn. Magn. Mater. 290(SI), 1355-1358 (2005). http://dx.doi.org/10.1016/j.jmmm. 2004.11.436

[25] L. Y. Shi, J. Z. Ruan, J. Zhang, Z. J. Zhao, H. B. Gao and U. Hartmann, "Enhancement of giant magneto-impedance effect in $\mathrm{Ni}_{80} \mathrm{Fe}_{20} / \mathrm{SiO}_{2} / \mathrm{Cu}$ composite wires", Physica B 404(20), 3766-3770 (2009). http://dx.doi.org/10.1016/j.physb. 2009.06.139 